\title{
Em defesa da pesquisa lenta numa época de ciência acelerada
}

Maria do Mar Pereira

\section{OpenEdition}

\section{Journals}

Edição electrónica

URL: http://journals.openedition.org/rccs/7548

DOI: $10.4000 /$ rccs. 7548

ISSN: 2182-7435

Editora

Centro de Estudos Sociais da Universidade de Coimbra

\section{Edição impressa}

Data de publição: 1 setembro 2018

Paginação: 197-202

ISSN: 0254-1106

\section{Refêrencia eletrónica}

Maria do Mar Pereira, "Em defesa da pesquisa lenta numa época de ciência acelerada », Revista

Crítica de Ciências Sociais [Online], 116 | 2018, posto online no dia 31 julho 2018, consultado o 24 setembro 2020. URL : http://journals.openedition.org/rccs/7548; DOl : https://doi.org/10.4000/rccs. 7548 


\section{Revisões críticas}

\section{Em defesa da pesquisa lenta numa época de ciência acelerada}

\section{Reflexões a partir de Pais, José Machado (2016), Enredos sexuais, tradição e mudança: as mães, os zecas $e$ as sedutoras de além-mar. Lisboa: Imprensa de Ciências Sociais, 325 pp.}

Vivemos na era da academia rápida, eficiente, dinâmica, produtiva. Em Portugal, como em tantos outros países, institucionalizou-se nos últimos anos uma cultura académica que eu e outras/os autoras/es temos apelidado de performativa (Ball, 2000; Blackmore e Sachs, 2003; M. M. Pereira, 2017). Esta transformação não só alterou as nossas práticas diárias de produção de conhecimento científico, como teve também um outro efeito muito significativo: reconfigurou profundamente as definições dominantes daquilo que conta como conhecimento científico de qualidade e valor. A atividade académica passou a ser, em muitos contextos, (re)tratada como trabalho que deve ter como objetivo atingir graus de produtividade o mais elevados possível, e cuja qualidade pode e deve ser avaliada em função do número de produtos produzidos (sejam eles artigos, projetos financiados, comunicações, patentes, ou alunas/os satisfeitas/os) (Ampudia de Haro, 2017; M. M. Pereira, 2017; T. S. Pereira, 2004). De forma a poder monitorizar a produtividade de indivíduos e organizações (e assim proceder à sua recompensa ou sanção), torna-se necessário montar e manter estruturas complexas de auditoria - veja-se, por exemplo, os relatórios e planos de atividade que somos regularmente chamadas/ /os a produzir. Estas estruturas exigem e produzem a medição, comparação, ranking e monetarização contínua da produção individual e coletiva (Ampudia de Haro, 2017; Knowles e Burrows, 2014), sempre por referência a um lema fundamental: quanto mais e quanto mais depressa produzirmos, melhor.

Dizer, neste contexto académico acelerado, que alguém produziu um estudo lento pode parecer ofensa ou injúria. Mas José Machado Pais assume essa caracterização explícita e orgulhosamente no seu novo livro Enredos sexuais, tradição e mudança: as mães, os zecas $e$ as sedutoras de além-mar (2016). Num vídeo de apresentação da obra, descreve-a como "uma peça de artesanato, na medida em que foi elaborado com um tempo lento" (Pais, 2017). Para o autor, "a lentidão do tempo que caracteriza as pesquisas de pendor artesanal" era algo que podia jogar "a [s] eu favor" (Pais, 2016: 11). De facto, essa lentidão é a grande força e o principal contributo do livro, não só pelo conhecimento riquíssimo que gera, mas também pela postura científica que promove - porque, como nos diz o autor, "aquele tempo [lento] [...] propicia [...] descobertas etnográficas [...], ao contrário daquelas pesquisas de terreno feitas a contrarrelógio que apenas questionam aquilo que pressupõe" (Pais, 2017). O livro é lento de muitas formas diferentes. É lento porque resulta de um longo e demorado trabalho de campo etnográfico sobre o movimento das "Mães de Bragança”. Desde a sua primeira incursão no terreno em Bragança em 2003, até à última visita em 2015, passaram mais de 
dez anos de trabalho de campo intermitente mas intenso em Trás-os-Montes e Espanha. Durante esse período, Machado Pais acumulou muita experiência de observação em casas de alterne e "cafés de subir", muitas conversas com "mães", clientes, prostitutas, autoridades locais, feiticeiras, proxenetas, jornalistas ou jovens, e muitas aventuras em lojas, feiras e festas... Tudo para nos ajudar a compreender este movimento altamente mediatizado, fundado em 2003 por um grupo de mulheres que, revoltadas com a infidelidade dos maridos, tentaram expulsar da região as trabalhadoras sexuais (maioritariamente) brasileiras que, na sua opinião, eram responsáveis por "desviar" estes homens. O livro é lento também porque não se precipita a formular uma análise sobre o seu objeto no calor do momento, mas toma o seu tempo. Ele chega-nos às mãos quase 15 anos depois da eclosão da polémica que estuda, "o tempo necessário para ganharmos uma boa distância em relação à realidade que se pretende" pesquisar (Pais, 2016: 12). Isto permite a Machado Pais analisar o movimento das "Mães de Bragança” não como um objeto concreto e claramente demarcado, mas sim como ponto de partida para uma análise mais vasta do modo como as pessoas negoceiam género, sexualidade e identidade nacional quando "as forças da tradição se enfrentam com as da mudança” (ibidem: 9) e quando "os costumes" locais se enfrentam com "o que vem de fora", num mundo globalizado (ibidem: 286).

O livro é lento porque se detém nos pormenores e saboreia os detalhes, deixando-os guiar a descoberta e discussão, resistindo à pressão para analisar apenas o que é útil e à tentação de chegar rapidamente a uma conclusão. Isto é possível porque o deambular de Machado Pais pelas ruas de Bragança e a região vizinha é, também ele, lento. É em passo vagaroso que ele passa à frente de uma certa casa de alterne, olhando-a de soslaio como quem estava ali por acaso à procura de outra coisa, talvez como muitos dos homens que visitam aquela casa, e outras parecidas, pela primeira vez. É de forma lenta, mas animada e atribulada, quase cinematográfica, que Machado Pais, "assumindo o papel de detetive” (2016: 58), percorre a lista telefónica e as ruas de Bragança à procura de um potencial entrevistado, dantes proprietário de uma das mais conhecidas casas de alterne da cidade, mas agora um recluso em prisão domiciliária. Este passo lento, a demorar-se nos pormenores, permite-lhe reparar em pequenas coisas que servem como mote para grandes análises. Um exemplo disso é a música pimba "Ó Maria dá-me o bife", que Machado Pais ouve um dia, por acaso, tocar numa feira, e que acaba por inspirar um capítulo inteiro (o quarto dos oito capítulos que compõem o livro), no qual analisa normas de género e sexualidade através das letras de várias músicas e poemas populares.

Esta lentidão do livro tem vários efeitos. Ela prende e enreda-nos na análise, e tornamo-nos parte dos "enredos sexuais" que dão título ao livro. Nós próprias/os sentimos o desejo e a desilusão porque, com a sua análise lenta, Machado Pais consegue dar vida às situações e sensações que descreve. Isso aconteceu comigo de forma particularmente memorável no capítulo seis, intitulado "O chá de amarração" e dedicado à discussão de um segredo. Machado Pais levanta um pouco o véu sobre esse segredo... mas logo a seguir baixa-o, nega-se a satisfazer-nos, deixando-nos suspensas/os, tensos/as, inquietas/os. De repente, parece que vai revelar algo mais e nós começamos, sedentos/as e curiosas/os, a ler as frases mais depressa, sustendo a respiração à espera da revelação que vai atenuar a tensão... Para logo a seguir nos ser negada essa 
revelação, deixando o nosso desejo, de novo frustrado, ainda mais intenso e incontrolável. A lenta descrição etnográfica desse sedutor segredo consegue, assim, reproduzir a dinâmica de sedução que está no centro desse segredo, e que anima as relações sociais e sexuais que o livro analisa. A lentidão da análise permite também outra coisa importante - relacionar fenómenos e níveis de análise que são habitualmente estudados separadamente: chá e música pimba, anedotas e tragédia, violência e saudade, telenovelas e literatura, sexualidade e história, colonialismo e intrigas locais, tradição e novas tecnologias. Estes e outros temas aparecem no livro enredados e interligados, tal como existem na vida quotidiana. Eles são um novelo emaranhado que, fio a fio, Machado Pais vai desembaraçando, às vezes com a ajuda de pertinentes teorias e conceitos das mais diversas ciências sociais, mas muitas vezes com a ajuda do acaso, do fortuito, da coincidência - a conversa que desperta uma nova pergunta, a música que despoleta uma associação diferente, o objeto na loja que gera uma ideia e soluciona um enigma. A lentidão do livro permite, além disso, evitar interpretações fáceis e explorar paradoxos: o homem viril que, chegado à casa de alterne, só deseja conversar e receber mimos; mães sacrificadas e esposas oprimidas que são, ao mesmo tempo, detentoras de uma imensa influência; sedutoras (supostamente) todas-poderosas que nem sempre têm o poder de controlar as suas próprias vidas, condições de trabalho ou passaportes. A exploração que Machado Pais faz destes paradoxos ilustra bem aquela que é, a meu ver, uma das características analiticamente mais significativas, e socialmente mais trágicas, dos regimes de género em sociedades sexistas. Embora haja assimetrias de poder inegáveis nesses regimes, muitas vezes não é possível identificar de forma clara e inequívoca os/as vencedores/as e os/as vencidos/as, porque as normas de género e sexualidade dominantes são tóxicas para toda a gente (M. M. Pereira, 2012). No caso da comunidade aqui analisada, estas normas produzem desigualdades, desencontros e desgostos, alguns profundamente trágicos, que ninguém deseja inteiramente mas que todas/os alimentam de forma mais ou menos consciente. A exploração destes paradoxos cruciais torna o livro, ele próprio, num paradoxo - é ao mesmo tempo triste e divertido, sério e frívolo, científico e cinematográfico. É, em parte, por isso mesmo que o livro consegue suscitar em cada leitor/a reflexões tão diversas, ricas e fecundas.

A mim, o livro levou-me a pensar sobre temas que nós, cientistas sociais a trabalhar na universidade performativa, não podemos deixar de debater. $\mathrm{Na}$ minha própria etnografia da academia portuguesa, ouvi muitas/os entrevistadas/os - desde pessoas estabelecidas a colegas em início de carreira - explicar que estão sob tamanha pressão para produzir tanto, que não têm tempo para pensar a fundo sobre aquilo que produzem, fazer a investigação que realmente desejam ou ler o trabalho produzido por outros/as colegas (M. M. Pereira, 2017). Tenho argumentado em diferentes publicações (M. M. Pereira, 2016, 2017) que este regime de aceleração e intensificação do trabalho, e o clima generalizado de cansaço e alienação que ele gera, estão a ter consequências extremamente nocivas a muitos níveis. Por um lado, têm impactos epistémicos, afetando a qualidade do conhecimento que produzimos: que conhecimento é possível criar quando não se tem tempo suficiente para pensar, ler, debater e fazer peer review? Por outro, têm efeitos sobre as pessoas que produzem esse conhecimento, afetando a nossa saúde física, mental e emocional, a nossa vitalidade intelectual, a nossa vida 
pessoal, e as relações de troca e cooperação entre colegas. A situação é, em alguns contextos (e eu incluo nesta categoria o contexto português), tão severa, que há autoras/es a falar da existência de "uma catástrofe psicossocial e somática" (Gill e Donaghue, 2016: 91) entre académicos/as, uma "profunda crise somática e afetiva que ameaça destruir-nos" (Burrows, 2012:355; ver também Mountz et al., 2015).

Sei que José Machado Pais, como qualquer outro/a colega, também se sente profundamente pressionado pela "lufa-lufa" (Pais, 2010) académica. No entanto, ele parece neste livro tentar resistir à pressa que essa lufa-lufa induz. Sente-se que este era o livro que ele queria escrever, ao ritmo que lhe fazia sentido - um ritmo que exige tempo para deambular, parar e pensar, e que nos encoraja também a nós, leitoras/es, a parar um pouco para pensar e deambular com ele. É, em parte por isso, que este livro é tão importante, refrescante e urgente. Infelizmente, muitos/as colegas em Portugal e no estrangeiro - especialmente aqueles/ /as com contratos temporários e precários - não têm condições de trabalho que lhes permitam fazer pesquisa lenta e demorada.
Isto coloca desafios especialmente difíceis para as ciências sociais, e em particular para a etnografia (Briggs, 2018). Será que este método, tantas vezes lento e demorado, é compatível com a universidade performativa? Até que ponto, e com que sacrifícios, é possível fazer etnografia ao ritmo da ciência acelerada: uma etnografia em modo multi-tasking (que temos de conciliar com uma carga intensa de aulas e burocracia académica), com resultados numerosos e rápidos, que possam ser convertidos em artigos para revistas internacionais de renome, e que venham depois a ter impactos sociais claros e mensuráveis (Ampudia de Haro, 2017; Knowles e Burrows, 2014)? O que acontece à etnografia quando a fazemos com pressa? Essas são interrogações que temos de debater em conjunto urgentemente. Este livro de José Machado Pais é uma importante inspiração para este debate, porque nos lembra as coisas extraordinárias que é possível fazer quando há tempo para parar, pensar e deambular. Em tempos de aceleração, essa lentidão pode ser a maior das descobertas.

Maria do Mar Pereira

\section{Referências bibliográficas}

Ampudia de Haro, Fernando (2017), "O impacto de (não) ter impacto: para uma sociologia crítica das publicações científicas”, Revista Crítica de Ciências Sociais, 113, 83-106.

Ball, Stephen J. (2000), "Performativities and Fabrications in the Education Economy: Towards the Performative Society?", The Australian Educational Researcher, 27(2), 1-23.

Blackmore, Jill; Sachs, Judyth (2003), "Managing Equity Work in the Performative University", Australian Feminist Studies, 18(41), 141-162.
Briggs, Daniel (2018), "On the Frontline: Ethnography in a Time of Neoliberalised Learning and Teaching", Discover Society, 6 de março. Consultado a 02.04.2018, em https://discoversociety.org/2018/2003/2006/ on-the-frontline-ethnography-in-a-time-ofneoliberalised-learning-and-teaching/.

Burrows, Roger (2012), "Living with the H-Index? Metric Assemblages in the Contemporary Academy", The Sociological Review, 60(2), 355-372.

Gill, Rosalind; Donaghue, Ngaire (2016), "Resilience, Apps and Reluctant Individualism: 
Technologies of Self in the Neoliberal Academy", Women's Studies International Forum, 54, 91-99.

Knowles, Caroline; Burrows, Roger (2014), "The Impact of Impact”, Etnográfica, 18(2), 237-254.

Mountz, Alison; Bonds, Anne; Mansfield, Becky; Loyd, Jenna; Hyndman, Jennifer; Walton-Roberts, Margaret; Basu, Ranu; Whitson, Risa; Hawkins, Roberta; Hamilton, Trina; Curran, Winifred (2015), "For Slow Scholarship: A Feminist Politics of Resistance through Collective Action in the Neoliberal University", ACME, 14(4), 1235-1259.

Pais, José Machado (2010), Lufa-lufa quotidiana: ensaios sobre cidade, cultura e vida urbana. Lisboa: Imprensa de Ciências Sociais.

Pais, José Machado (2016), Enredos sexuais, tradição e mudança: as mães, os zecas e as sedutoras de além-mar. Lisboa: Imprensa de Ciências Sociais.
Pais, José Machado (2017), "Livro do mês - Maio 2017”, Biblioteca do ISCTE-IUL. Consultado a 02.04.2018, em https://www.iscte-iul. $\mathrm{pt} /$ calendars/item/273/enredos-sexuaistradicao-mudanca-maes-zecas-sedutorasde-alemmar.

Pereira, Maria do Mar (2012), Fazendo género no recreio: a negociação do género em espaço escolar. Lisboa: Imprensa de Ciências Sociais.

Pereira, Maria do Mar (2016), "Struggling within and beyond the Performative University: Articulating Activism and Work in an 'Academia without Walls', Women's Studies International Forum, 54, 100-110.

Pereira, Maria do Mar (2017), Power, Knowledge and Feminist Scholarship: An Ethnography of Academia. London: Routledge.

Pereira, Tiago Santos (2004), "Processos de governação da ciência: o debate em torno do modelo de financiamento das unidades de investigação em Portugal", Revista Crítica de Ciências Sociais, 70, 5-32.

\section{Maria do Mar Pereira}

Department of Sociology, University of Warwick Social Sciences Building, Coventry, CV4 7AL, United Kingdom

Contacto: m.d.m.pereira@warwick.ac.uk 
